\title{
Natural myside bias is independent of cognitive ability
}

\author{
Keith E. Stanovich \\ University of Toronto, Canada \\ Richard F. West \\ James Madison University, Harrisonburg, VA, USA
}

\begin{abstract}
Natural myside bias is the tendency to evaluate propositions from within one's own perspective when given no instructions or cues (such as withinparticipants conditions) to avoid doing so. We defined the participant's perspective as their previously existing status on four variables: their sex, whether they smoked, their alcohol consumption, and the strength of their religious beliefs. Participants then evaluated a contentious but ultimately factual proposition relevant to each of these demographic factors. Myside bias is defined between-participants as the mean difference in the evaluation of the proposition between groups with differing prior status on the variable. Whether an individual difference variable (such as cognitive ability) is related to the magnitude of the myside bias is indicated by whether the individual difference variable interacts with the between-participants status variable. In two experiments involving a total of over 1400 university students $(n=1484)$ and eight different comparisons, we found very little evidence that participants of higher cognitive ability displayed less natural myside bias. The degree of myside bias was also relatively independent of individual differences in thinking dispositions. We speculate that ideas from memetic theory and dualprocess theory might help to explain why natural myside bias is quite dissociated from individual difference variables.
\end{abstract}

A recurring theme in the critical thinking literature is that it is important for a critical thinker to be able to decouple their prior beliefs and opinions from the evaluation of evidence and arguments (Baron, 1991, 2000; Evans, 2002;

Correspondence should be addressed to Richard F. West, Department of Psychology, James Madison University, Harrisonburg, Virginia 22807, USA. E-mail: WestRF@jmu.edu

This research was supported by grants from Social Sciences and Humanities Research Council of Canada and the Canada Research Chairs program to Keith E. Stanovich. Jonathan Baron and Paul Klaczynski are thanked for their comments on an earlier version of the manuscript.

(C) 2006 Psychology Press, an imprint of the Taylor \& Francis Group, an Informa business http://www.psypress.com/tar DOI: $10.1080 / 13546780600780796$ 
Norris \& Ennis, 1989; Paul, 1984, 1987; Perkins, 1995; Stanovich, 1999, 2004; Sternberg, 1997, 2001, 2003; Wade \& Tavris, 1993). Such skills are also the foundation of rational thought and wisdom (Baltes \& Staudinger, 2000; Evans, 2002; Perkins, Jay, \& Tishman, 1993; Sternberg, 2001). A large research literature indicates that people have difficulty in decoupling from prior opinion and belief. So-called myside bias has been amply demonstrated in numerous empirical studies. People evaluate evidence, generate evidence, and test hypotheses in a manner biased towards their own opinions (Baron, 1991, 1995; Greenhoot, Semb, Colombo, \& Schreiber, 2004; Kuhn, 1991; Perkins, 1985; Perkins, Farady, \& Bushey, 1991; Toplak $\&$ Stanovich, 2003). Likewise, people have difficulty evaluating conclusions that conflict with what they think they know about the world (Evans, 2002; Evans, Barston, \& Pollard, 1983; Evans, Newstead, Allen, \& Pollard, 1994; Klauer, Musch, \& Naumer, 2000). Nickerson (1998) has reviewed the literature on many of these effects and uses the term confirmation bias to refer to the demonstrated phenomenon of "inappropriate bolstering of hypotheses or beliefs whose truth is in question" (p. 175). This inappropriate bolstering can be driven by prior belief (as in myside bias) or prior knowledge (as in the belief bias effect in syllogistic reasoning, see Klauer et al., 2000). In all cases it involves an inability to decouple knowledge or belief from evaluative information processing tasks.

Researchers have begun to examine the individual difference variables that predict skill at decoupling and avoiding confirmation biases. For example, the well-known belief bias effect in syllogistic reasoning (Evans et al., 1983; Klauer et al., 2000) is the tendency for judgements of logical validity to be contaminated by prior knowledge of the world. Judgements of logical validity can be thrown off if the conclusions of the syllogism contradict real-world knowledge (more generally, when validity and the facts expressed in the conclusion conflict). Stanovich and West $(1997,1998)$ and Sá, West, and Stanovich (1999) found moderate correlations between cognitive ability and the ability to avoid such biases (see also Gilinsky \& Judd, 1994; Handley, Capon, Beveridge, Dennis, \& Evans, 2004; Kokis, Macpherson, Toplak, West, \& Stanovich, 2002; Simoneau \& Markovits, 2003; however, see Torrens, Thompson, \& Cramer, 1999).

In contrast to these results, in the preponderance of the work published by Klaczynski and colleagues (Klaczynski, 1997; Klaczynski \& Gordon, 1996; Klaczynski, Gordon, \& Fauth, 1997; Klaczynski \& Lavallee, 2005; Klaczynski \& Narasimham, 1998; Klaczynski \& Robinson, 2000), they have found that a form of myside bias was unrelated to cognitive ability. They presented participants with flawed hypothetical experiments that led to either opinion-consistent or opinion-inconsistent conclusions and evaluated the quality of the reasoning used when the participants critiqued the flaws in the experiments. Klaczynski and colleagues found that verbal ability was related 
to the quality of the reasoning in both the opinion-consistent and opinioninconsistent conditions. In these experiments, myside bias effects were also observed-participants found more flaws when the experiment's conclusions were inconsistent than when they were consistent with their opinions and beliefs. However, verbal ability was not correlated with the magnitude of the myside bias effect - even though it was correlated with overall levels of reasoning in each of the different conditions considered separately.

There is a critical difference in experimental procedure that might explain the difference in data pattern between the studies of myside bias by the Stanovich group (e.g., Sá et al., 1999; Stanovich \& West, 1997, 1998) and the Klaczynski group (Klaczynski, 1997; Klaczynski \& Robinson, 2000). That factor is whether the participants were explicitly and specifically instructed to ignore prior knowledge and belief in the task. In the former studies, where belief bias effects were predicted by cognitive ability, the participants were explicitly instructed to decouple from their prior beliefs and opinions. For example, in a reasoning task where participants evaluated syllogisms in which logical validity conflicted with the factual truth of the contents of the syllogism, Sá et al. (1999) gave the participants the following instructions: "In the following problems, you will be given two premises which you must assume are true. A conclusion from the premises then follows. You must decide whether the conclusion follows logically from the premises or not. You must suppose that the premises are all true and limit yourself only to the information contained in the premises. This is very important. Decide if the conclusion follows logically from the premises, assuming the premises are true, and circle your response." Such instructions strongly emphasise the necessity of decoupling prior knowledge and prior belief from the validity evaluation task. In contrast, in the experiments by Klaczynski and colleagues, the participants simply evaluated the strength of the conclusion that could be drawn from an experiment as well as the persuasiveness of the experiment without any explicit instruction to set aside their prior opinions about the issue that is the focus of the experiment.

Explicit instructions to decouple (see Evans et al., 1994) probably sensitise the participant that detaching from prior opinion is a necessary requirement of the task, and participants of differing cognitive abilities have different levels of computational power available for the override operations that make decoupling possible (Carruthers, 2002; Dienes \& Perner, 1999; Evans \& Over, 2004; Geary, 2005; Nichols \& Stich, 2003; Perner, 1991; Stanovich, 1999, 2004; Stanovich \& West, 2000). This creates the correlation between cognitive ability and the magnitude of the myside bias demonstrated in the experiments of the Stanovich group. In contrast, the Klaczynski paradigm does not sensitise the participant to the necessity for decoupling in order to perform optimally in the task. In the absence of such instructions, participants of high cognitive ability may be no more likely to recognise the need for decontextualisation than are those of low cognitive 
ability. Such an explanation of the discrepant findings would be consistent with theoretical views that emphasise the difference between typical information processing and maximal information processing (Ackerman, 1996; Ackerman \& Heggestad, 1997).

The procedure used by the Klaczynski group - not explicitly instructing participants on the need to detach from prior belief - might be described as more naturalistic (although see Bereiter, 2002, and Stanovich, 2004, for discussions of the increasing need for cued decontextualised thought in the modern world). However, even their paradigm contains cues that might help participants recognise the need for decoupling. The experiments are run within participants - that is, each participant evaluates both opinionconsistent and opinion-inconsistent experiments.

Many investigators have noted that within-participants manipulations draw the participant's attention to the variable of interest (e.g., Fischhoff, Slovic, \& Lichtenstein, 1979; Kahneman, 2000; Kahneman \& Frederick, 2002; Kahneman \& Tversky, 1996; LeBoeuf \& Shafir, 2003). It is interesting to note that belief bias effects in syllogistic reasoning (in which correlations with cognitive ability have been found previously) are usually run within participants. After responding to a series of conflict syllogisms it becomes increasingly apparent that there are two things (logic and believability) to be traded off. Thus the very design provides an important cue that part of the experimental demand is to deal with this trade-off.

But, as Kahneman (2000) has noted, "much of life resembles a betweenparticipants experiment" (p. 682). Between-participants designs might be even more naturalistic. Thus, a between-participants design, in not containing cues to the variable of interest, might even further reduce the relationship between myside bias and individual difference variables. For example, LeBoeuf and Shafir (2003) found that framing effects were associated with need for cognition in a within-participants design but not in a between-participants design.

In the present studies, we conducted a rather pure test of what we term natural myside bias. Natural myside bias is the tendency to evaluate propositions from within one's own perspective, when given no instructions to avoid doing so and when there are no implicit cues (such as withinparticipants conditions) that do so. In this investigation, we defined the participant's perspective as their previously existing status on four variables: their sex, whether they smoked, their alcohol consumption, and the strength of their religious beliefs. Participants then evaluated a proposition relevant to each of these demographic factors. Myside bias is defined betweenparticipants as the mean difference in the evaluation of the proposition between groups with differing prior status on the variable. Whether an individual difference variable (such as cognitive ability for example) is related to the magnitude of the myside bias is indicated by whether the individual 
difference variable interacts with the between-participants status variable. In Experiment 1 we examine the relation of myside bias to cognitive ability.

\section{EXPERIMENT 1}

\section{Method}

\section{Participants}

The participants were 439 undergraduate students (106 males and 333 females) recruited through an introductory psychology participant pool at a medium-sized state university. Their mean age was 18.9 years $(S D=2.2)$. The majority of these students were freshmen (262 students) or sophomores (120 students), and almost $90 \%$ of them identified themselves as White (391 White; 16 African American; 20 Asian American; 12 Other).

\section{Prior demographic status}

The demographics form filled out by the students included four questions about their status on four likely sources of natural myside bias (e.g., "I currently am a nonsmoker/smoker"). The questions, which are listed in the left-hand column of Table 1, concerned their sex, alcohol consumption, whether or not they smoked, and the strength of their religious belief. These four questions were used to dichotomise the sample.

The gender question dichotomised the sample into 106 males and 333 females. The alcohol consumption question dichotomised the sample into 99 nondrinkers and 340 drinkers. ${ }^{1}$ The third dichotomisation was smoker $(n=74)$ versus nonsmoker $(n=340)$. Finally, a dichotomisation of God certain $(n=275)$ versus God not certain $(n=164)$ was formed by assigning those who reported that they were "certain that God exists" (Table 1) to the God certain group and the remaining students to the God not certain group.

\section{Myside bias propositions}

Subsequent to filling out the demographic form and some reasoning problems that were not part of the present investigation, participants were asked to indicate the extent to which they agreed or disagreed with each of four statements (e.g., "Secondhand smoke is a health hazard for nonsmokers"). The statements, which are listed in the right-hand column of Table 1, corresponded to the sex, alcohol consumption, smoking, and the strength of religious belief prior status questions. Participants responded

\footnotetext{
${ }^{1}$ The difference between the ages of the nondrinkers and drinkers was not significant: mean ages of $18.9(S D=2.19)$ and $18.9(S D=3.2)$ respectively, $t(437)=0.05, p<n s$.
} 
TABLE 1

Prior demographic status questions and corresponding myside bias propositions

Prior demographicstatus question

1. Sex: Male/Female

2. During the last month, how many times have you consumed alcohol?

3. I currently am a (check one) nonsmoker/ smoker.

4. My feelings concerning the existence of God are:

(1) I am certain that God exists,

(2) I am pretty sure that God exists

(3) I think that there probably is a God

(4) I am not sure whether God exists or not

(5) I think that there probably is not a God

(6) I am pretty sure that God does not exist

(7) I am certain that God does not exist.
Corresponding myside bias proposition

1. The gap in salary between men and women generally disappears when they are employed in the same position.

2. Students who drink alcohol while in college are more likely to become alcoholic in later life.

3. Secondhand smoke is a health hazard for nonsmokers.

4. Religious people are generally more honest than nonreligious people.

Participants responded to the myside bias propositions using the following 6-point scale: Strongly Agree (6), Moderately Agree (5), Slightly Agree (4), Slightly Disagree (3), Moderately Disagree (2), and Strongly Disagree (1).

using the following 6-point scale: Strongly Agree (6), Moderately Agree (5), Slightly Agree (4), Slightly Disagree (3), Moderately Disagree (2), and Strongly Disagree (1).

\section{Cognitive ability measure}

SAT scores. Students were asked to indicate their verbal, mathematical, and total SAT scores on the demographics form. The mean reported verbal SAT score of the students was $589(S D=66)$, the mean reported mathematical SAT score was $589(S D=68)$, and mean total SAT score was $1177(S D=104)$. These self-reported scores closely match the averages for this institution (582, 587, and 1169, respectively) (James Madison University Office of Institutional Research, 1999-2000). A further indication of the validity of such self-reported scores was obtained by Stanovich and West (1998) who found that the correlation between a vocabulary test and self-reported SAT total scores (.49) was quite similar to the .51 correlation between the vocabulary test and verified total SAT scores in a previous investigation using the same vocabulary measure (West \& Stanovich, 1991). The more reliable total SAT score will be used in the analyses to be reported in the experiment that follows. 
The SAT test taken by these participants is a 3-hour paper-and-pencil exam used for university admissions testing. The standardised scores on the verbal and mathematical sections are added together to form the total score. The scores of the students matriculating to this institution are roughly one standard deviation above the mean of all of the prospective university students taking the test. Our reliance on the SAT as a measure of cognitive ability is justified by the fact that it loads highly on psychometric $g$ (general intelligence) (Frey \& Detterman, 2004) and that it is strongly associated with working memory - the quintessential indicator of computational capacity in cognitive science (Colom, Rebollo, Palacios, Juan-Espinosa, \& Kyllonen, 2004; Conway, Kane, \& Engle, 2003; Engle, 2002; Engle, Tuholski, Laughlin, \& Conway, 1999; Kane, Hambrick, Tuholski, Wilhelm, Payne, \& Engle, 2004).

For the purposes of the analyses described below, the 227 students with SAT scores below the median (1190) were assigned to the low-SAT group, and the 212 remaining students were assigned to the high-SAT group.

\section{Results}

Table 2 illustrates that each of the four prior demographic status variables significantly predicted responses on the corresponding myside bias propositions. For example, the 106 males were significantly more favourable towards the salary proposition ("The gap in salary between men and women

TABLE 2

Mean myside bias proposition scores as a function of prior demographic status

\begin{tabular}{|c|c|c|c|c|c|c|}
\hline \multirow[b]{2}{*}{ Prior demographic status } & \multicolumn{2}{|c|}{ Status 1} & \multicolumn{2}{|c|}{ Status 2} & \multirow[b]{2}{*}{$t(437)$} & \multirow[b]{2}{*}{ Cohen's a } \\
\hline & $M$ & $S D$ & $M$ & $S D$ & & \\
\hline $\begin{array}{l}\text { Sex } \\
\quad \text { Status 1: Male }(n=106) \\
\text { Status 2: Female }(n=333)\end{array}$ & 3.11 & 1.16 & 2.59 & 1.17 & $4.04 * *$ & 0.45 \\
\hline $\begin{array}{l}\text { Drinking } \\
\quad \text { Status 1: Nondrinker }(n=99) \\
\text { Status 2: Drinker }(n=340)\end{array}$ & 3.52 & 1.34 & 2.69 & 1.83 & $5.36 * *$ & 0.61 \\
\hline $\begin{array}{l}\text { Smoking } \\
\text { Status 1: Nonsmoker }(n=365) \\
\text { Status 2: Smoker }(n=74)\end{array}$ & 5.46 & 0.98 & 5.14 & 1.13 & $2.52 *$ & 0.29 \\
\hline $\begin{array}{l}\text { Belief in God } \\
\text { Status 1: Certain }(n=275) \\
\text { Status 2: Not Certain }(n=164)\end{array}$ & 3.31 & 1.27 & 2.63 & 1.41 & $5.24 * *$ & 0.49 \\
\hline
\end{tabular}


generally disappears when they are employed in the same position") $(M=3.11, S D=1.16)$ than were the 333 females $(M=2.59, S D=1.17)$, $t(437)=4.04, p<.001$. Likewise, prior status on the drinking, smoking, and belief in God questions significantly predicted responses on the corresponding myside bias propositions. All of the effects were in the expected direction.

Thus, robust myside biases were observed on all of the propositions. Males were more likely to endorse the salary proposition; nondrinkers were more likely to endorse the proposition "Students who drink alcohol while in college are more likely to become alcoholic in later life"; nonsmokers were more likely to endorse the proposition "Secondhand smoke is a health hazard for nonsmokers"; and students who expressed a higher level of certainty that God existed were more likely to endorse the proposition "Religious people are generally more honest than nonreligious people". The magnitude of the effect sizes (Cohen's $d \mathrm{~s}$ of $.45, .61, .29$, and .49) were generally in the moderate range. Note that our paradigm does not allow one to pinpoint bias in individuals or in one particular group, but instead gives a between-participants indication that a particular magnitude of bias is present somewhere. It indicates that people with a particular stance or group status evaluate propositions relevant to that group status differently.

The next series of analyses examined whether the magnitude of the myside bias effect was moderated by cognitive ability. This was done by examining, in an ANOVA context, whether the degree of myside bias on each of the propositions interacted with SAT scores (see Table 3). In each

TABLE 3

ANOVA (prior status variable $\times$ SAT) and mean proposition scores as a function of status variable and SAT

\begin{tabular}{lclll}
\hline Source & $F(1,435)$ & & \multicolumn{2}{c}{ Mean (number in cell) } \\
\hline Sex & $16.73^{* * *}$ & & Male & Female \\
SAT & $<1$ & SAT Low & $3.17(46)$ & $2.64(181)$ \\
Sex $\times$ SAT & $<1$ & SAT High & $3.07(60)$ & $2.53(154)$ \\
Drinking & $32.49^{* * *}$ & & Nondrinker & Drinker \\
SAT & $14.19^{* *}$ & SAT Low & $3.24(58)$ & $2.59(169)$ \\
Drinking $\times$ SAT & 2.13 & SAT High & $3.90(41)$ & $2.80(171)$ \\
Smoking & $6.88^{* *}$ & & Nonsmoker & Smoker \\
SAT & $<1$ & SAT Low & $5.42(196)$ & $5.03(31)$ \\
Smoking $\times$ SAT & $<1$ & SAT High & $5.50(169)$ & $5.21(43)$ \\
Belief in God & $26.27^{* * *}$ & & Certain & Not Certain \\
SAT & $<1$ & SAT Low & $3.39(153)$ & $2.65(74)$ \\
Belief in God $\times$ SAT & $<1$ & SAT High & $3.22(122)$ & $2.61(90)$ \\
\hline
\end{tabular}

${ }^{*} p<.05 ;{ }^{* *} p<.01 ; * * * p<.001$. 
analysis, SAT (low, high; see Method section of this experiment) and a prior status variable (sex, drinking, smoking, belief in God) were examined in a $2 \times 2$ factorial ANOVA. As expected given the results in Table 2, the main effect for each prior status variable was significant $(p<.01$ to $p<.001)$. The main effect of SAT reached significance only for the drinking proposition. Higher SAT participants were more likely to agree with the proposition "students who drink alcohol while in college are more likely to become alcoholic in later life". However, the critical statistic in these analyses is the test of significance for the interaction, because it indicates whether the degree of myside bias was related to cognitive ability. Here the results were unambiguous. None of the four interactions reached statistical significance. The $F$ for interaction was less than 1 in three of the four analyses, and the slight but nonsignificant interaction $(p=.15)$ in the analysis of the drinking proposition was in the unexpected direction: participants of higher cognitive ability displayed a slightly larger myside bias effect. Thus, these analyses provided no evidence at all that myside bias effects are smaller for students of higher cognitive ability.

Although all four of the prior status variables were treated dichotomously in these analyses, the drinking and belief in God variables were actually measured on more continuous scales. We ran another ANOVA in which the drinking variable was partitioned into four categories of roughly equal frequency (nondrinkers, drinking 1-3 times a month, drinking 4-6 times a month, drinking $>6$ times a month). The interaction in the 4 (drinking status variable) $\times 2$ (SAT) ANOVA was not statistically significant, $F(3,431)=1.45, p>.20$. The belief in God variable was likewise partitioned into four categories (certain, pretty sure, probably, not sure or even more doubtful). The first category (certain) was over-represented in terms of numbers of participants (275). The interaction in the 4 (belief in God variable) $\times 2$ (SAT) ANOVA was not statistically significant, $F(3,431)=0.40, n s$.

The significance of the four interactions was also tested in four regression analyses in which SAT was used as a continuous variable rather than as a dichotomous variable (as in the ANOVA). The status variable by SAT interaction failed to reach significance in each of these analyses, thus converging with the ANOVA outcomes.

Finally, we attempted to see whether amalgamating performance across the four items would reveal any individual difference patterns. We constructed a standardised measure of myside projection by multiplying the $z$-score on each of the propositions by the $z$-score on the corresponding status variable. Each of the status variables was scored in the direction where higher cross products indicated more projection of myside opinions. The cross product was then summed. The summed cross-product displayed a nonsignificant correlation of .064 with the total SAT score. 


\section{EXPERIMENT 2}

Because the dichotomisation of the demographic variables was often lopsided, some of the cell estimates in the ANOVAs in Table 3 were based on modest sample sizes (e.g., 31, 41). In Experiment 2 we more than doubled the sample size in order to increase the power of the experiment, thus increasing the probability of detecting the critical interaction. Additionally, in light of the failure to observe a relation between cognitive ability and myside bias in Experiment 1, we examined a different class of variable. Thinking dispositions that are somewhat dissociated from intelligence such as actively openminded thinking have been found to predict the magnitude of belief bias in both formal (Newstead, Handley, Harley, Wright, \& Farrelly, 2004; Stanovich \& West, 1997, 1998) and informal reasoning paradigms (Klaczynski et al., 1997; Klaczynski \& Robinson, 2000; Sá, Kelley, Ho, \& Stanovich, 2005). We examined two such thinking dispositions in Experiment 2.

\section{Method}

\section{Participants}

The participants were 1045 undergraduate students (319 males and 726 females) recruited through an introductory psychology participant pool at a medium-sized state university. Their mean age was 19.0 years $(S D=1.8)$. The majority of these students were freshmen (631 students) or sophomores (284 students), and almost 90\% of them identified themselves as White (921 White; 29 African American; 57 Asian American; 38 Other).

\section{Prior demographic status}

The gender question dichotomised the sample into 319 males and 726 females. The alcohol consumption question dichotomised the sample into 200 nondrinkers and 845 drinkers. $^{2}$ The third dichotomisation was smoker $(n=169)$ versus nonsmoker $(n=876)$. Finally, a dichotomisation of God certain $(n=821)$ versus God not certain $(n=224)$ students was formed by assigning those who reported that they were "certain that God exists" (Table 1) to the God certain group and the remaining students to the God not certain group.

\footnotetext{
${ }^{2}$ The mean age of the nondrinkers $(M=18.8, S D=1.06)$ was very close to that of the highalcohol group $(M=19.1, S D=1.77)$ even though the difference was significant due to the very large sample size, $t(1043)=2.00, p=.046$.
} 


\section{Myside bias propositions}

Subsequent to filling out the demographic form, participants completed a questionnaire that consisted of a number of subscales assessing styles of epistemic regulation, including the thinking disposition measures described below and additional scales that were not part of the present investigation. Four myside bias propositions, which were the same as those used in Experiment 1 (see Table 1), were embedded in this questionnaire.

\section{Cognitive ability measure}

SAT scores. Students were asked to indicate their verbal, mathematical, and total SAT scores on the demographics form. The mean reported verbal SAT score of the students was $585(S D=69)$, the mean reported mathematical SAT score was $588(S D=68)$, and mean total SAT score was $1172(S D=104)$. The more reliable total SAT score will be used in the analyses to be reported in the experiment that follows. For the purposes of some of the analysis described below, the 532 students with SAT scores below the median (1190) were assigned to the low-SAT group, and the 513 remaining students were assigned to the high-SAT group.

\section{Thinking dispositions measures}

Actively-openminded thinking ( $A O T$ ) scale. The items on this scale were intermixed with the need for cognition items (described below) and with other scales not part of the present investigation. The actively openminded thinking scale was composed for 41 items drawn from a variety of sources: 10 items from a flexible thinking scale developed by Stanovich and West (1997); 8 items from the Openness-Values facet of the Revised NEO Personality Inventory (Costa \& McCrae, 1992); 9 items measuring dogmatism (Paulhus \& Reid, 1991; Robinson, Shaver, \& Wrightsman, 1991; Troldahl \& Powell, 1965); 3 items from the categorical thinking subscale of Epstein and Meier's (1989) constructive thinking inventory; 9 items from the belief identification scale developed by Sá et al. (1999); 2 items from a counterfactual thinking scale developed by Stanovich and West (1997). All items were scored in the direction that higher scores represented a greater tendency toward openminded thinking. Examples of items are "People should always take into consideration evidence that goes against their beliefs", "Certain beliefs are just too important to abandon no matter how good a case can be made against them" (reverse scored), "no one can talk me out of something I know is right" (reverse scored). The response format for each item in the questionnaire was: Strongly Agree (6), Moderately Agree (5), Slightly Agree (4), Slightly Disagree (3), Moderately 
Disagree (2), and Strongly Disagree (1). The score on the scale was obtained by summing the responses to the 41 items (Mean $=170.7, S D=18.2)$. The split-half reliability of the actively-openminded thinking scale (SpearmanBrown corrected) was .75 and Cronbach's alpha was .83 .

For the purposes of some of the analysis described below, the 522 students with AOT scores below the median were assigned to the low-AOT group, and the 523 remaining students were assigned to the high-AOT.

Need for cognition scale. The 18-item need for cognition scale published by Cacioppo, Petty, Feinstein, and Jarvis (1996) was employed in this study. Sample items include: "The notion of thinking abstractly is appealing to me", and "I would prefer a task that is intellectual, difficult, and important to one that is somewhat important but does not require much thought". Participants in this study completed a questionnaire consisting of a number of self-report subscales. The items on this scale were intermixed with the AOT scale items and with other scales not part of the present investigation. The response format for each item in the questionnaire was: Strongly Agree (6), Moderately Agree (5), Slightly Agree (4), Slightly Disagree (3), Moderately Disagree (2), and Strongly Disagree (1). The split-half reliability of the need for cognition scale (Spearman-Brown corrected) was .87 and Cronbach's alpha was .88 . The mean score was $68.7(S D=11.9)$.

For the purposes of some of the analysis described below, the 539 students scores below the median were assigned to the low-need for cognition group, and the 506 remaining students were assigned to the highneed for cognition group.

\section{Results}

Table 4 indicates that robust myside biases were observed on all of the propositions. For example, the 319 males were significantly more favourable towards the salary proposition ("The gap in salary between men and women generally disappears when they are employed in the same position") $(M=2.94, S D=1.21)$ than were the 726 females $(M=2.47, S D=1.17)$, $t(1043)=5.89, p<.001$. Likewise, prior status on the drinking, smoking, and belief in God questions significantly predicted responses on the corresponding myside bias propositions. All of the effects were in the expected direction. The magnitude of the effect sizes (Cohen's $d \mathrm{~s}$ of $.40, .67$, .35 , and .43$)$ were generally in the moderate range.

The analyses presented in Table 5 examined whether the magnitude of the myside bias effect was moderated by cognitive ability or thinking dispositions. In the first set of analyses, SAT and a prior status variable (sex, drinking, smoking, belief in God) were examined in $2 \times 2$ factorial 
TABLE 4

Mean myside bias proposition scores as a function of prior demographic status

\begin{tabular}{|c|c|c|c|c|c|c|}
\hline \multirow[b]{2}{*}{ Prior demographic status } & \multicolumn{2}{|c|}{ Status 1} & \multicolumn{2}{|c|}{ Status 2} & \multirow[b]{2}{*}{$t(1043)$} & \multirow[b]{2}{*}{ Cohen's a } \\
\hline & $M$ & $S D$ & $M$ & $S D$ & & \\
\hline $\begin{array}{l}\text { Sex } \\
\text { Status 1: Male }(n=319) \\
\text { Status 2: Female }(n=726)\end{array}$ & 2.94 & 1.21 & 2.47 & 1.17 & $5.89 *$ & 0.40 \\
\hline $\begin{array}{l}\text { Drinking } \\
\quad \text { Status 1: Nondrinker }(n=200) \\
\text { Status 2: Drinker }(n=845)\end{array}$ & 3.64 & 1.44 & 2.70 & 1.40 & $8.45^{*}$ & 0.67 \\
\hline $\begin{array}{l}\text { Smoking } \\
\text { Status 1: Nonsmoker }(n=876) \\
\text { Status 2: Smoker }(n=169)\end{array}$ & 5.53 & 0.97 & 5.12 & 1.18 & $4.79^{*}$ & 0.35 \\
\hline $\begin{array}{l}\text { Belief in God } \\
\text { Status 1: Certain }(n=636) \\
\text { Status 2: Not Certain }(n=409)\end{array}$ & 3.15 & 1.40 & 2.56 & 1.38 & $6.75^{*}$ & 0.43 \\
\hline
\end{tabular}

${ }^{*} p<.001$.

ANOVAs. As expected given the results in Table 4, the main effect for each prior status variable was significant (all $p$ s $<.001$ ). As in Experiment 1 , the main effect of SAT reached significance for the drinking proposition. Higher SAT participants were more likely to agree with the proposition "students who drink alcohol while in college are more likely to become alcoholic in later life". In Experiment 2 the main effect of SAT was also significant for the gender proposition. Higher SAT participants were less likely to agree with the proposition "the gap in salary between men and women generally disappears when they are employed in the same position".

However, as in Experiment 1, the critical statistic in these analyses is the test of significance for the interaction, because it indicates whether the degree of myside bias was related to cognitive ability. The $F$ for interaction was less than 1 in three of the four analyses. The interaction did reach significance when sex was the prior status variable $(p=.036)$. Higher SAT participants displayed a smaller myside bias effect. However, the magnitude of the interaction effect was small (eta squared $=.004$ ). Thus, as in Experiment 1, these analyses provided very little evidence indicating that myside bias effects are smaller for students of higher cognitive ability.

Although all four of the prior status variables were treated dichotomously in these analyses, the drinking and belief in God variables were actually measured on more continuous scales. We ran another ANOVA in which the drinking variable was partitioned into four categories of roughly equal frequency (nondrinkers, drinking 1-3 times a month, drinking 4-6 times a month, drinking $>6$ times a month). The interaction in the 4 
TABLE 5

ANOVAs and mean proposition scores

\begin{tabular}{|c|c|c|c|c|}
\hline \multirow{2}{*}{$\begin{array}{l}\text { Source } \\
\text { Sex }\end{array}$} & \multirow{2}{*}{$\frac{F(1,1041)}{38.51 * * *}$} & & \multicolumn{2}{|c|}{ Mean (number in cell) } \\
\hline & & & Male & Female \\
\hline SAT & $7.02 * *$ & SAT Low & $3.15(138)$ & 2.49 (394) \\
\hline Sex $\times$ SAT & $4.40 *$ & SAT High & $2.77(181)$ & $2.45(332)$ \\
\hline Drinking & $73.07 * * *$ & & Nondrinker & Drinker \\
\hline SAT & $5.78 *$ & SAT Low & $3.50(107)$ & $2.59(425)$ \\
\hline Drinking $\times$ SAT & $<1$ & SAT High & $3.81(93)$ & $2.81(420)$ \\
\hline Smoking & $22.58 * * *$ & & Nonsmoker & Smoker \\
\hline SAT & $<1$ & SAT Low & $5.54(444)$ & $5.06(88)$ \\
\hline Smoking $\times$ SAT & $<1$ & SAT High & $5.52(432)$ & $5.20(81)$ \\
\hline Belief in God & $42.18 * * *$ & & Certain & Not Certain \\
\hline SAT & 2.61 & SAT Low & $3.21(355)$ & 2.64 (177) \\
\hline Belief in God $\times$ SAT & $<1$ & SAT High & $3.08(281)$ & $2.49(232)$ \\
\hline Sex & $30.30 * * *$ & & Male & Female \\
\hline AOT & $34.28 * * *$ & AOT Low & $3.20(175)$ & $2.65(347)$ \\
\hline Sex $\times$ AOT & 2.44 & AOT High & $2.62(144)$ & $2.31(379)$ \\
\hline Drinking & $48.54 * * *$ & & Nondrinker & Drinker \\
\hline AOT & $13.09 * * *$ & AOT Low & $3.88(134)$ & $2.76(388)$ \\
\hline Drinking $\times$ AOT & $7.10 * *$ & AOT High & $3.15(66)$ & $2.65(457)$ \\
\hline Smoking & $23.11 * * *$ & & Nonsmoker & Smoker \\
\hline AOT & 1.50 & AOT Low & $5.48(439)$ & $5.07(83)$ \\
\hline Smoking $\times$ AOT & $<1$ & AOT High & $5.58(437)$ & $5.17(86)$ \\
\hline Belief in God & $15.33 * * *$ & & Certain & Not Certain \\
\hline AOT & $101.81 * * *$ & AOT Low & $3.46(386)$ & $3.22(136)$ \\
\hline Belief in God × AOT & 1.48 & AOT High & $2.68(250)$ & $2.22(273)$ \\
\hline Sex & $35.78 * * *$ & & Male & Female \\
\hline NCog & $4.71 *$ & NCog Low & 3.04 (155) & $2.54(384)$ \\
\hline Sex $\times$ NCog & $<1$ & NCog High & $2.84(164)$ & $2.39(342)$ \\
\hline Drinking & $71.61^{* * *}$ & & Nondrinker & Drinker \\
\hline NCog & $<1$ & NCog Low & $3.73(97)$ & $2.70(442)$ \\
\hline Drinking $\times$ NCog & $<1$ & NCog High & $3.55(103)$ & $2.71(403)$ \\
\hline Smoking & $23.10 * * *$ & & Nonsmoker & Smoker \\
\hline $\mathrm{NCog}$ & $<1$ & NCog Low & $5.53(457)$ & $5.07(82)$ \\
\hline Smoking $\times$ NCog & $<1$ & NCog High & $5.53(419)$ & $5.17(87)$ \\
\hline Belief in God & $45.11 * * *$ & & Certain & Not Certain \\
\hline $\mathrm{NCog}$ & $29.90 * * *$ & NCog Low & $3.33(335)$ & $2.85(204)$ \\
\hline Belief in God $\times$ NCog & 1.54 & NCog High & $2.96(301)$ & $2.26(205)$ \\
\hline
\end{tabular}

${ }^{*} p<.05 ;{ }^{* *} p<.01 ; * * * p<.001$.

$\mathrm{AOT}=$ actively openminded thinking, $\mathrm{NCog}=$ need for cognition. 
(drinking status variable) $\times 2$ (SAT) ANOVA was not statistically significant, $F(3,1037)=0.22$, $n s$. The belief in God variable was likewise partitioned into four categories (certain, pretty sure, probably, not sure or even more doubtful). The first category (certain) was over-represented in terms of numbers of participants (636). The interaction in the 4 (belief in God variable) $\times 2$ (SAT) ANOVA was not statistically significant, $F(3,1037)=0.15$, ns.

The conclusions were reinforced by the results of four regression analyses in which SAT was used as a continuous variable rather than as a dichotomous variable as in the ANOVA. The status variable by SAT interaction failed to reach significance in each of the analyses. This included the analysis of sex as a status variable, where the interaction failed to reach significance $(p=.068)$ in the regression analysis.

Finally, we attempted to see whether amalgamating performance across the four items would reveal any individual difference patterns. We constructed a standardised measure of myside projection by multiplying the $z$-score on each of the propositions by the $z$-score on the corresponding status variable. Each of the status variables was scored in the direction where higher cross-products indicated more projection of myside opinions. The cross-product was then summed. The summed cross-product displayed a nonsignificant correlation of .050 with the total SAT score.

The next two sets of analyses examined whether the thinking dispositions actively openminded thinking and need for cognition moderated the degree of myside bias. One of the four interactions involving actively openminded thinking was statistically significant and none of the interactions involving need for cognition was significant. On the drinking proposition students high in actively openminded thinking displayed less myside bias.

These conclusions were reinforced by the results of eight regression analyses in which actively openminded thinking and need for cognition were used as a continuous variables with each of the four status variables. Six of the eight interactions failed to reach significance. The status variable by actively openminded thinking interaction $(p=.012)$ and the status variable by need for cognition interaction $(p=.041)$ both reached significance for the drinking proposition. Students high in actively openminded thinking and high on need for cognition displayed less myside bias.

\section{GENERAL DISCUSSION}

In the two experiments reported here we found very little evidence that individuals higher in cognitive ability were better able to avoid myside bias. None of the four critical interactions in Experiment 1 was statistically significant. In Experiment 2 - a study with considerable power because of its large sample size - only one of four critical interactions was significant, and 
its magnitude was quite small ( $p=.036$ with a sample size of 1045 , and an eta squared of .004). Furthermore, across the two experiments, none of the eight regression tests for interaction was statistically significant.

On the face of it, the failure to find that cognitive ability predicted the degree of myside bias in these experiments seems incredibly surprising. Ever since Spearman (1904) first discovered positive manifold, intelligence indicators have correlated with a plethora of cognitive/personality traits and thinking abilities that are almost too large to enumerate (e.g., Ackerman, Kyllonen, \& Richards, 1999; Deary, 2001; Deary, Whiteman, Starr, Whalley, \& Fox, 2004; Lubinski, 2000, 2004; Lubinski \& Humphreys, 1997). We think it critical that our paradigm included two factors that make it a probe of what we term natural myside bias. First, the target propositions were embedded within a questionnaire that contained no instructions hinting that the task involved the need to avoid bias, decontextualise, or detach from one's own perspective. Second, the degree of bias is measured between participants, thus giving no within-participants comparative cues that our focus is on the bias displayed towards a particular proposition.

Our reason for thinking that the lack of relation between cognitive ability and myside bias in these experiments is due to these two factors is that experiments that have included instructions to decontextualise and withinparticipants measures of bias have found such associations (e.g., Gilinsky \& Judd, 1994; Newstead et al., 2004; Sá et al., 1999; Stanovich \& West, 1997, 1998). Additionally, as mentioned previously, using an evidence evaluation paradigm in which participants were not instructed to debias, Klaczynski (1997; Klaczynski \& Gordon, 1996; Klaczynski et al., 1997; Klaczynski \& Lavallee, 2005; Klaczynski \& Robinson, 2000) also found that myside bias failed to associate with cognitive ability. Other experiments measuring something close to natural myside bias have suggested the same thing. For example, Toplak and Stanovich (2003) had participants generate arguments relevant to controversial issues (e.g., should people be allowed to sell their organs). They also assessed where the individual stood on the issues in question. They found a substantial myside bias on the task (people tended to give more arguments in favour of their position than against), but the degree of myside bias was not correlated with cognitive ability. In another study, Sá et al. (2005) looked at the quality of causal reasoning in an informal reasoning paradigm based on the work of Kuhn (1991, 1993). They had people describe their causal theory for a particular social phenomenon (e.g., why do ex-prisoners return to crime) and the evidence for and against their theories. Evidence types were scored for the quality of causal reasoning. The key finding was that the distribution of argument types was remarkably similar for participants of high and low intelligence.

In a naturalistic reasoning situation, participants of high cognitive ability may be no more likely to recognise the need for decontextualisation than are 
participants of low cognitive ability. Receiving instructions to decontextualise may short-circuit the need to exercise the higher-level thinking dispositions that make one prone to recognise situations where detachment might be advantageous. This speculation would be consistent with theoretical views that emphasise the separability of the algorithmic level of processing (indexed by intelligence) and the intentional level of processing (indexed by thinking dispositions; see Stanovich, 1999, 2002, 2004). To understand the sources and correlates of natural myside bias it is possible that investigations need to focus less on cognitive ability and more on epistemic regulation at the intentional level of analysis (Berg \& Klaczynski, 1996; Klaczynski, 2004; Schommer-Aikins, 2004; Sinatra \& Pintrich, 2003). However, the results of Experiment 2 were disappointing in this respect. In only one of four comparisons (the drinking proposition) did actively openminded thinking moderate the degree of myside bias (although the direction of the effect was the right one). None of the critical interactions involving need for cognition was significant, although the regression analyses did indicate one significant interaction effect (again involving the drinking proposition).

Thus, myside bias largely failed to associate with well-known thinking dispositions (actively openminded thinking, need for cognition) in the same manner that it failed to associate with a measure of cognitive ability (SAT scores). It is possible that an explanation of this finding might be found by combining some concepts from the emerging science of memetics-the science of the epidemiology of idea-sized units called memes (see Aunger, 2000, 2002; Blackmore, 1999; Dawkins, 1993; Dennett, 1991, 1995; Distin, 2005) - with those of dual-process theory (Evans, 1984, 2003, in press; Evans \& Over, 1996; Sloman, 1996, 2002; Stanovich, 1999, 2004).

For the same reason that genes in our genome cooperate (Ridley, 2000), memetic theory suggests that resident beliefs are selecting for a cooperator-someone like them. This accounts for the ubiquitous myside bias effects found in this experiment and in many others cited abovebeliefs contradicting previously residing beliefs are not easily assimilated (see Dole \& Sinatra, 1998; Sinatra, Southerland, McConaughy, \& Demastes, 2003). Such a view also accounts for results showing that although there are large differences between belief domains in how much myside bias they generate (some domains generate much myside bias and others little), individual difference findings indicate that there is little domain generality in myside bias. That is, a person showing high belief bias in one domain is not necessarily likely to show it in another (Toplak \& Stanovich, 2003). Thus, it is not people who are characterised by more or less myside bias, but beliefs that differ in the degree of myside bias they engender-that differ in how strongly they are structured to repel contradictory ideas. 
This speculation is consistent with the findings of our two studies. General individual difference characteristics that are posited to permeate large areas of cognitive functioning (e.g., intelligence, thinking dispositions such as need for cognition) were rather poor predictors of the degree of myside bias displayed on the various propositions. Cognitive ability measures such as the SAT are indices of the computational power (decoupling ability, see Stanovich, 2004) of the analytic system in dualprocess theories (System 2; see Evans, 2003, in press; Stanovich, 1999; Stanovich \& West, 2000, 2003). Likewise, thinking dispositions such as actively openminded thinking and need for cognition reflect the intentionallevel processes of epistemic regulation associated with System 2. Neither of these are mechanisms that seem related to natural myside bias.

In contrast to intelligence and thinking dispositions, belief in God reflects not computational power nor a generic mechanism of epistemic regulation but instead reflects an interlocking knowledge structure - a memeplex. As a knowledge structure, it is of course available for an access "call" by serial production systems operating in System 2 for example. But well-instantiated knowledge structures such as religious memeplexes are, we speculate, probably strongly subject to automatic triggering from System 1 (or TASS, see Evans, 2003; Stanovich, 2004) when stimuli related to the memeplex's many interlocking idea units appear. For example, religious memeplexes might be automatically called to bias any proposition that is highly related to their interlocking propositions (gender relations, drug use, threats to belief in God, etc.)

We are suggesting that in natural myside bias situations, bias is largely a function of the memeplexes subject to call from System 1 and is little moderated by decontextualising operations carried out by System 2. This is why myside bias is so little related to System 2 processing indices such as cognitive ability (algorithmic-level functioning) or thinking dispositions (intentional-level functioning). The degree of bias shown is a function of the memeplexes subject to automatic call and not individual differences in System 2 functioning. In contrast to natural myside bias situations, when people are explicitly cued to detach from their current perspective, individual differences in their proclivities to do so (thinking dispositions like actively openminded thinking) and their capacity to do so (algorithmiclevel decoupling abilities indexed by general intelligence indices) come to the fore and predict the degree of myside bias displayed. Thus, we speculate that natural myside bias has a different processing logic from processing under explicit instructions to detach from one's current perspective.

Manuscript received 12 October 2005

Revised manuscript received 3 April 2006

First published online 22 July 2006 


\section{REFERENCES}

Ackerman, P., Kyllonen, P., \& Richards, R. (Eds.). (1999). Learning and individual differences: Process, trait, and content determinants. Washington, DC: American Psychological Association.

Ackerman, P. L. (1996). A theory of adult development: Process, personality, interests, and knowledge. Intelligence, 22, 227-257.

Ackerman, P. L., \& Heggestad, E. D. (1997). Intelligence, personality, and interests: Evidence for overlapping traits. Psychological Bulletin, 121, 219-245.

Aunger, R. (Ed.). (2000). Darwinizing culture: The status of memetics as a science. Oxford, UK: Oxford University Press.

Aunger, R. (2002). The electric meme: A new theory of how we think. New York: Free Press.

Baltes, P. B., \& Staudinger, U. M. (2000). Wisdom: A metaheuristic (pragmatic) to orchestrate mind and virtue toward excellence. American Psychologist, 55, 122-136.

Baron, J. (1991). Beliefs about thinking. In J. Voss, D. Perkins, \& J. Segal (Eds.), Informal reasoning and education (pp. 169-186). Hillsdale, NJ: Lawrence Erlbaum Associates Inc.

Baron, J. (1995). Myside bias in thinking about abortion. Thinking and Reasoning, 1, 221 - 235.

Baron, J. (2000). Thinking and deciding (3rd ed.). Cambridge, MA: Cambridge University Press.

Bereiter, C. (2002). Education and mind in the knowledge age. Mahwah, NJ: Lawrence Erlbaum Associates Inc.

Berg, C. A., \& Klaczynski, P. A. (1996). Practical intelligence and problem solving: Searching for perspectives. In E. Blanchard-Fields \& T. M. Hess (Eds.), Perspectives on cognition in adulthood and aging (pp. 323-357). New York: McGraw-Hill.

Blackmore, S. (1999). The meme machine. New York: Oxford University Press.

Cacioppo, J. T., Petty, R. E., Feinstein, J., \& Jarvis, W. (1996). Dispositional differences in cognitive motivation: The life and times of individuals varying in need for cognition. Psychological Bulletin, 119, 197-253.

Carruthers, P. (2002). The cognitive functions of language. Behavioral and Brain Sciences, 25, $657-726$.

Colom, R., Rebollo, I., Palacios, A., Juan-Espinosa, M., \& Kyllonen, P. C. (2004). Working memory is (almost) perfectly predicted by $g$. Intelligence, 32, 277-296.

Conway, A. R. A., Kane, M. J., \& Engle, R. W. (2003). Working memory capacity and its relation to general intelligence. Trends in Cognitive Science, 7, 547-552.

Costa, P. T., \& McCrae, R. R. (1992). Revised NEO personality inventory. Odessa, FL: Psychological Assessment Resources.

Dawkins, R. (1993). Viruses of the mind. In B. Dahlbom (Ed.), Dennett and his critics (pp. 13-27). Cambridge, MA: Blackwell.

Deary, I. J. (2001). Intelligence: A very short introduction. Oxford, UK: Oxford University Press.

Deary, I. J., Whiteman, M. C., Starr, J. M., Whalley, L. J., \& Fox, H. C. (2004). The impact of childhood intelligence on later life: Following up the Scottish Mental Surveys of 1932 and 1947. Journal of Personality and Social Psychology, 86, 130-147.

Dennett, D. C. (1991). Consciousness explained. Boston: Little Brown.

Dennett, D. C. (1995). Darwin's dangerous idea: Evolution and the meanings of life. New York: Simon \& Schuster.

Dienes, Z., \& Perner, J. (1999). A theory of implicit and explicit knowledge. Behavioral and Brain Sciences, 22, 735-808.

Distin, K. (2005). The selfish meme. Cambridge, UK: Cambridge University Press.

Dole, J. A., \& Sinatra, G. M. (1998). Reconceptualizing change in the cognitive construction of knowledge. Educational Psychologist, 33, 109-128. 
Engle, R. W. (2002). Working memory capacity as executive attention. Current Directions in Psychological Science, 11, 19-23.

Engle, R. W., Tuholski, S. W., Laughlin, J. E., \& Conway, A. R. A. (1999). Working memory, short-term memory, and general fluid intelligence: A latent-variable approach. Journal of Experimental Psychology: General, 128, 309-331.

Ennis, R. H. (1987). A taxonomy of critical thinking dispositions and abilities. In J. Baron \& R. Sternberg (Eds.), Teaching thinking skills: Theory and practice (pp. 9-26). New York: W. H. Freeman.

Epstein, S., \& Meier, P. (1989). Constructive thinking: A broad coping variable with specific components. Journal of Personality and Social Psychology, 57, 332-350.

Evans, J. St. B. T. (1984). Heuristic and analytic processes in reasoning. British Journal of Psychology, 75, 451-468.

Evans, J. St. B. T. (2002). The influence of prior belief on scientific thinking. In P. Carruthers, S. Stich, \& M. Siegal (Eds.), The cognitive basis of science (pp. 193-210). Cambridge, UK: Cambridge University Press.

Evans, J. St. B. T. (2003). In two minds: Dual-process accounts of reasoning. Trends in Cognitive Sciences, 7, 454-459.

Evans, J. St. B. T. (in press). The heuristic-analytic theory of reasoning: Extension and evaluation. Psychonomic Bulletin and Review.

Evans, J. St. B. T., Barston, J., \& Pollard, P. (1983). On the conflict between logic and belief in syllogistic reasoning. Memory \& Cognition, 11, 295-306.

Evans, J. St. B. T., Newstead, S., Allen, J., \& Pollard, P. (1994). Debiasing by instruction: The case of belief bias. European Journal of Cognitive Psychology, 6, 263-285.

Evans, J. St. B. T., \& Over, D. E. (1996). Rationality and reasoning. Hove, UK: Psychology Press.

Evans, J. St. B. T., \& Over, D. E. (2004). If. Oxford, UK: Oxford University Press.

Fischhoff, B., Slovic, P., \& Lichtenstein, S. (1979). Subjective sensitivity analysis. Organizational Behavior and Human Performance, 23, 339-359.

Frey, M. C., \& Detterman, D. K. (2004). Scholastic assessment or g? The relationship between the scholastic assessment test and general cognitive ability. Psychological Science, 15(6), $373-378$.

Geary, D. C. (2005). The origin of the mind: Evolution of brain, cognition, and general intelligence. Washington, DC: American Psychological Association.

Gilinsky, A., \& Judd, B. B. (1994). Working memory and bias in reasoning across the life span. Psychology and Aging, 9, 356-371.

Greenhoot, A. F., Semb, G., Colombo, J., \& Schreiber, T. (2004). Prior beliefs and methodological concepts in scientific reasoning. Applied Cognitive Psychology, 18, 203-221.

Handley, S. J., Capon, A., Beveridge, M., Dennis, I., \& Evans, J. St. B. T. (2004). Working memory, inhibitory control and the development of children's reasoning. Thinking and Reasoning, 10, $175-195$.

Horn, J. L., \& Noll, J. (1997). Human cognitive capabilities: Gf-Gc theory. In D. Flanagan, J. Genshaft, \& P. Harrison (Eds.), Contemporary intellectual assessment: Theories, tests, and issues (pp. 53-91). New York: Guilford Press.

Jones, W., Russell, D., \& Nickel, T. (1977). Belief in the paranormal scale: An objective instrument to measure belief in magical phenomena and causes. JSAS Catalog of Selected Documents in Psychology, 7(100), Ms. No. 1577.

Kahneman, D. (2000). A psychological point of view: Violations of rational rules as a diagnostic of mental processes. Behavioral and Brain Sciences, 23, 681-683.

Kahneman, D., \& Frederick, S. (2002). Representativeness revisited: Attribute substitution in intuitive judgement. In T. Gilovich, D. Griffin, \& D. Kahneman (Eds.), Heuristics and biases: The psychology of intuitive judgement (pp. 49-81). New York: Cambridge University Press. 
Kahneman, D., \& Tversky, A. (1996). On the reality of cognitive illusions. Psychological Review, 103, 582-591.

Kane, M. J., Hambrick, D. Z., Tuholski, S. W., Wilhelm, O., Payne, T., \& Engle, R. W. (2004). The generality of working memory capacity: A latent-variable approach to verbal and visuospatial memory span and reasoning. Journal of Experimental Psychology: General, 133, $189-217$.

Klaczynski, P. A. (1997). Bias in adolescents' everyday reasoning and its relationship with intellectual ability, personal theories, and self-serving motivation. Developmental Psychology, 33, 273-283.

Klaczynski, P. A. (2004). A dual-process model of adolescent development: Implications for decision making, reasoning, and identity. Advances in Child Development and Behavior, $32,73-123$.

Klaczynski, P. A., \& Gordon, D. H. (1996). Self-serving influences on adolescents' evaluations of belief-relevant evidence. Journal of Experimental Child Psychology, 62, 317-339.

Klaczynski, P. A., Gordon, D. H., \& Fauth, J. (1997). Goal-oriented critical reasoning and individual differences in critical reasoning biases. Journal of Educational Psychology, 89, $470-485$.

Klaczynski, P. A., \& Lavallee, K. L. (2005). Domain-specific identity, epistemic regulation, and intellectual ability as predictors of belief-based reasoning: A dual-process perspective. Journal of Experimental Child Psychology, 92, 1-24.

Klaczynski, P. A., \& Narasimham, G. (1998). Development of scientific reasoning biases: Cognitive versus ego-protective explanations. Developmental Psychology, 34, 175- 187.

Klaczynski, P. A., \& Robinson, B. (2000). Personal theories, intellectual ability, and epistemological beliefs: Adult age differences in everyday reasoning tasks. Psychology and Aging, 15, 400-416.

Klauer, K. C., Musch, J., \& Naumer, B. (2000). On belief bias in syllogistic reasoning. Psychological Review, 107, 852-884.

Kokis, J., Macpherson, R., Toplak, M., West, R. F., \& Stanovich, K. E. (2002). Heuristic and analytic processing: Age trends and associations with cognitive ability and cognitive styles. Journal of Experimental Child Psychology, 83, 26-52.

Kuhn, D. (1991). The skills of argument. Cambridge, UK: Cambridge University Press.

Kuhn, D. (1993). Connecting scientific and informal reasoning. Merrill-Palmer Quarterly, 38, $74-103$.

LeBoeuf, R. A., \& Shafir, E. (2003). Deep thoughts and shallow frames: On the susceptibility to framing effects. Journal of Behavioral Decision Making, 16, 77-92.

Lubinski, D. (2000). Scientific and social significance of assessing individual differences: "Sinking shafts at a few critical points". Annual Review of Psychology, 51, 405-444.

Lubinski, D. (2004). Introduction to the special section on cognitive abilities: 100 years after Spearman's (1904) “General Intelligence, Objectively Determined and Measured”. Journal of Personality and Social Psychology, 86, 96-111.

Lubinski, D., \& Humphreys, L. G. (1997). Incorporating general intelligence into epidemiology and the social sciences. Intelligence, 24, 159-201.

Newstead, S. E., Handley, S. J., Harley, C., Wright, H., \& Farrelly, D. (2004). Individual differences in deductive reasoning. Quarterly Journal of Experimental Psychology, 57A, $33-60$.

Nichols, S., \& Stich, S. P. (2003). Mindreading: An integrated account of pretence, selfawareness, and understanding other minds. Oxford, UK: Oxford University Press.

Nickerson, R. S. (1998). Confirmation bias: A ubiquitous phenomenon in many guises. Review of General Psychology, 2, 175-220.

Norris, S. P., \& Ennis, R. H. (1989). Evaluating critical thinking. Pacific Grove, CA: Midwest Publications. 
Paul, R. W. (1984). Critical thinking: Fundamental to education for a free society in North America: A new theory of knowledge, learning, and literacy. Educational Leadership, 42(1), $4-14$.

Paul, R. W. (1987). Critical thinking and the critical person. In D. N. Perkins, J. Lockhead, \& J. Bishop (Eds.), Thinking: The second international conference (pp. 373-403). Hillsdale, NJ: Lawrence Erlbaum Associates Inc.

Paulhus, D. L., \& Reid, D. B. (1991). Enhancement and denial in socially desirable responding. Journal of Personality and Social Psychology, 60, 307-317.

Perkins, D. N. (1985). Postprimary education has little impact on informal reasoning. Journal of Educational Psychology, 77, 562-571.

Perkins, D. N. (1995). Outsmarting IQ: The emerging science of learnable intelligence. New York: Free Press.

Perkins, D. N., Farady, M., \& Bushey, B. (1991). Everyday reasoning and the roots of intelligence. In J. Voss, D. Perkins, \& J. Segal (Eds.), Informal reasoning and education (pp. 83-105). Hillsdale, NJ: Lawrence Erlbaum Associates Inc.

Perkins, D. N., Jay, E., \& Tishman, S. (1993). Beyond abilities: A dispositional theory of thinking. Merrill-Palmer Quarterly, 39, 1-21.

Perner, J. (1991). Understanding the representational mind. Cambridge, MA: MIT Press.

Ridley, M. (2000). Mendel's demon: Gene justice and the complexity of life. London: Weidenfeld \& Nicolson.

Robinson, J. P., Shaver, P. R., \& Wrightsman, L. S. (1991). Measures of personality and social psychological attitudes (Vol. 1, pp. 560-564). San Diego, CA: Academic Press.

Sá, W., Kelley, C., Ho, C., \& Stanovich, K. E. (2005). Thinking about personal theories: Individual differences in the coordination of theory and evidence. Personality and Individual Differences, 38, 1149-1161.

Sá, W. C., West, R. F., \& Stanovich, K. E. (1999). The domain specificity and generality of belief bias: Searching for a generalizable critical thinking skill. Journal of Educational Psychology, 91, 497-510.

Schommer-Aikins, M. (2004). Explaining the epistemological belief system: Introducing the embedded systemic model and coordinated research approach. Educational Psychologist, 39, $19-30$.

Simoneau, M., \& Markovits, H. (2003). Reasoning with premises that are not empirically true: Evidence for the role of inhibition and retrieval. Developmental Psychology, 39, 964-975.

Sinatra, G., Southerland, S. A., McConaughy, F., \& Demastes, J. W. (2003). Intentions and beliefs in students' understanding and acceptance of biological evolution. Journal of Research in Science Teaching, 40, 510-528.

Sinatra, G. M., \& Pintrich, P. R. (2003). The role of intentions in conceptual change learning. In G. M. Sinatra \& P. R. Pintrich (Eds.), Intentional conceptual change (pp. 1-18). Mahwah, NJ: Lawrence Erlbaum Associates Inc.

Sloman, S. A. (1996). The empirical case for two systems of reasoning. Psychological Bulletin, $119,3-22$.

Sloman, S. A. (2002). Two systems of reasoning. In T. Gilovich, D. Griffin, \& D. Kahneman (Eds.), Heuristics and biases: The psychology of intuitive judgment (pp. 379-396). New York: Cambridge University Press.

Spearman, C. (1904). General intelligence, objectively determined and measured. American Journal of Psychology, 15, $201-293$.

Stanovich, K. E. (1999). Who is rational? Studies of individual differences in reasoning. Mahwah, NJ: Lawrence Erlbaum Associates Inc.

Stanovich, K. E. (2002). Rationality, intelligence, and levels of analysis in cognitive science: Is dysrationalia possible? In R. J. Sternberg (Ed.), Why smart people can be so stupid (pp. 124-158). New Haven, CT: Yale University Press. 
Stanovich, K. E. (2004). The robot's rebellion: Finding meaning in the age of Darwin. Chicago: University of Chicago Press.

Stanovich, K. E., \& West, R. F. (1997). Reasoning independently of prior belief and individual differences in actively open-minded thinking. Journal of Educational Psychology, 89, $342-357$.

Stanovich, K. E., \& West, R. F. (1998). Individual differences in rational thought. Journal of Experimental Psychology: General, 127, 161-188.

Stanovich, K. E., \& West, R. F. (2000). Individual differences in reasoning: Implications for the rationality debate? Behavioral and Brain Sciences, 23, 645-726.

Stanovich, K. E., \& West, R. F. (2003). Evolutionary versus instrumental goals: How evolutionary psychology misconceives human rationality. In D. Over (Ed.), Evolution and the psychology of thinking: The debate (pp. 171-230). Hove, UK: Psychology Press.

Sternberg, R. J. (1997). Thinking styles. Cambridge, UK: Cambridge University Press.

Sternberg, R. J. (2001). Why schools should teach for wisdom: The balance theory of wisdom in educational settings. Educational Psychologist, 36, 227-245.

Sternberg, R. J. (2003). Wisdom, intelligence, and creativity synthesized. Cambridge, UK: Cambridge University Press.

Toplak, M. E., \& Stanovich, K. E. (2003). Associations between myside bias on an informal reasoning task and amount of post-secondary education. Applied Cognitive Psychology, 17, $851-860$.

Torrens, D., Thompson, V. A., \& Cramer, K. M. (1999). Individual differences and the belief bias effect: Mental models, logical necessity, and abstract reasoning. Thinking and Reasoning, 5, 1-28.

Troldahl, V., \& Powell, F. (1965). A short-form dogmatism scale for use in field studies. Social Forces, 44, 211-215.

Wade, C., \& Tavris, C. (1993). Critical and creative thinking. New York: HarperCollins.

West, R. F., \& Stanovich, K. E. (1991). The incidental acquisition of information from reading. Psychological Science, 2, 325-330. 